\title{
The Feedback Control Strategy of the Takagi-Sugeno Fuzzy Car-Following Model with Two Delays
}

\author{
Cong Zhai, Weiming Liu, and Ling Huang \\ School of Civil Engineering and Transportation, South China University of Technology, Guangzhou, Guangdong 510640, China \\ Correspondence should be addressed to Weiming Liu; ctlwmjt@mail.scut.edu.cn
}

Received 28 March 2016; Accepted 13 June 2016

Academic Editor: Roberto Sacile

Copyright (c) 2016 Cong Zhai et al. This is an open access article distributed under the Creative Commons Attribution License, which permits unrestricted use, distribution, and reproduction in any medium, provided the original work is properly cited.

\begin{abstract}
Considering the driver's sensing the headway and velocity the different time-varying delays exist, respectively, and the sensitivity of drivers changes with headway and speed. Introducing the fuzzy control theory, a new fuzzy car-following model with two delays is presented, and the feedback control strategy of the new fuzzy car-following model is studied. Based on the Lyapunov function theory and linear matrix inequality (LMI) approach, the sufficient condition that the existence of the fuzzy controller is given making the closed-loop system is asymptotic, stable; namely, traffic congestion phenomenon can effectively be suppressed, and the controller gain matrix can be obtained via solving linear matrix inequality. Finally, the simulation examples verify that the method which suppresses traffic congestion and reduces fuel consumption and exhaust emissions is effective.
\end{abstract}

\section{Introduction}

Traffic congestion has become serious in recent years with the increase in traffic demand. Many traffic flow models were proposed to understand the mechanism of traffic congestion. Yu et al. [1] presented a new car-following model considering the velocity of a proceeding car. Zhang et al. [2] investigated the effect of the ideal speed of a driver on the stability of traffic flow. Sun et al. [3] verified that the average speed of a certain number of ahead cars could enhance the stability of traffic flow. Liu et al. [4] established a mixed car-truck car-following model based on the road of hybrid vehicles. Saifuzzaman et al. [5] investigated the behavior of drivers who use cell phones, which affects the stability of traffic flow. Tang et al. [6] proposed an improved car-following model under the intervehicle communication (IVC) system. Reichardt et al. [7] proved that the IVC system effectively improves vehicle safety and driving comfort. Kerner et al. [8] analyzed the stability of traffic flow under the traffic radio communication technology. Other studies on the car-following model are indicated in [9-12].

Although many scholars investigated car-following models, current studies on this topic are limited. (1) A previous article that regarded delays as constant is idealistic. A previous work [13] indicated that the delays of the driver should slowly fluctuate within a certain range. (2) Previous studies regarded sensitivity as a constant conflict in an actual situation. However, experimental analysis indicates that the sensitivity of the driver changes with headway and velocity. The sensitivity of drivers in crowded roads is generally slightly higher than that in open roads. Section 2 presents a class of Takagi-Sugeno (T-S) fuzzy time-varying delay car-following model to overcome the limitations of the traditional carfollowing model. In Section 3, the sufficient condition of the stability of T-S fuzzy car-following models is presented, and the design of the fuzzy controller is given in Section 4. Finally, through the simulation example verified that the method which suppresses the traffic congestion is effective (Figure 1).

\section{Model}

In this paper, a class of T-S fuzzy car-following systems with two delays is given. The fuzzy rules of $j$ can be described as follows:

$$
\begin{array}{ll}
R^{j}: \text { if } & v_{i}(t) \text { is } M_{1}^{j} \text { and if } y_{i}(t) \text { is } M_{2}^{j} \\
\text { then } & \dot{v}_{i}(t)=a_{i j}\left(F\left(y_{i}\left(t-\tau_{1}(t)\right)\right)-v_{i}\left(t-\tau_{2}(t)\right)\right)
\end{array}
$$




$$
\dot{y}_{i}(t)=v_{i-1}(t)-v_{i}(t)
$$$$
(i=1,2, \ldots, N) \text {, }
$$

where $M_{k}^{j}, k=1,2, j=1,2, \ldots, r$, are the fuzzy sets, $y_{i}(t)>$ 0 is the headway between vehicle $i-1$ and vehicle $i$ at time $t$, $v_{i}(t)$ is the instantaneous velocity of vehicle $i$ at time $t, a_{i j}$ is the sensitivity of the driver of vehicle $i$ under the rule $j, F(\cdot)$ is the optimal velocity function, and $\tau_{1}(t), \tau_{2}(t)$ are the time delay functions in sensing the headway and velocity, respectively, which satisfy the following expression:

$$
\begin{aligned}
0 & <\tau_{i}(t)<\bar{\tau}_{i}, \\
\dot{\tau}_{i}(t) & <d_{i}<1,
\end{aligned}
$$

$$
i=1,2 \text {, }
$$

where $\bar{\tau}_{1}, \bar{\tau}_{2}, d_{1}, d_{2}$ are known constants and $\bar{\tau}_{1}, \bar{\tau}_{2}$ are the maximum delays of sensing headway and speed, respectively, which initialized $y_{i}(t), v_{i}(t)$ as follows:

$$
\begin{aligned}
& y_{i}(t)=\varphi(t), t \in\left[0, \bar{\tau}_{1}\right] \\
& v_{i}(t)=\phi(t), t \in\left[0, \bar{\tau}_{2}\right] \\
& i=1,2, \ldots, N
\end{aligned}
$$

where $\varphi(t), \phi(t)$ are the continuous differentiable functions.

The general model for the fuzzy control system is expressed as follows:

$$
\begin{aligned}
& \dot{v}_{i}(t) \\
& =\frac{\sum_{j=1}^{r} \omega_{j}\left(v_{i}, y_{i}\right)\left(a_{i j}\left(F\left(y_{i}\left(t-\tau_{1}(t)\right)\right)-v_{i}\left(t-\tau_{2}(t)\right)\right)\right)}{\sum_{j=1}^{r} \omega_{j}\left(x_{i}(t), y_{i}(t)\right)}, \\
& \dot{y}_{i}(t)=v_{i-1}(t)-v_{i}(t) \quad(i=1,2, \ldots, N),
\end{aligned}
$$

where $\omega_{j}\left(v_{i}, y_{i}\right)=\prod_{k=1}^{2} M_{k}^{j}\left(v_{i}, y_{i}\right)$, where $M_{k}^{j}\left(v_{i}, y_{i}\right)$ is membership degree of $\left(v_{i}, y_{i}\right)$ for fuzzy set $M_{k}^{j}$. If we set $h_{i}\left(v_{i}, y_{i}\right)=$ $\omega_{j}\left(v_{i}, y_{i}\right) / \sum_{j=1}^{r} \omega_{j}\left(v_{i}, y_{i}\right)$, then (4) can be rewritten as follows:

$$
\begin{aligned}
& \dot{v}_{i}(t)=\sum_{j=1}^{r} h_{j}\left(v_{i}, y_{i}\right) \\
& \cdot\left(a_{i j}\left(F\left(y_{i}\left(t-\tau_{1}(t)\right)\right)-v_{i}\left(t-\tau_{2}(t)\right)\right)\right) \\
& \dot{y}_{i}(t)=v_{i-1}(t)-v_{i}(t) \quad(i=1,2, \ldots, N),
\end{aligned}
$$

where $h_{j}\left(v_{i}, y_{i}\right) \geq 0$ and $\sum_{j=1}^{r} h_{j}\left(v_{i}, y_{i}\right)=1$.

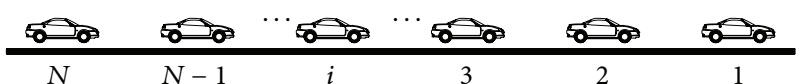

Figure 1: Platoon of $N$ cars running on a single lane.

The following nonlinear optimal velocity function is selected:

$$
F\left(y_{i}(t)\right)=\frac{v_{\max }}{2}\left(\tanh \left(y_{i}(t)-y_{c}\right)+\tanh \left(y_{c}\right)\right),
$$

where $v_{\max }$ represents the maximum speed and $y_{c}$ represents the safe distance.

Assuming that the head car runs with constant speed $v_{0}$, the stable state of the fuzzy car-following model (5) can be expressed as follows:

$$
\left[v_{i}^{*}, y_{i}^{*}\right]^{T}=\left[\begin{array}{ll}
v_{0} & F^{-1}\left(v_{0}\right)
\end{array}\right]^{T} .
$$

By defining error variables $\bar{y}_{i}(t)=y_{i}(t)-y_{i}^{*}$ and $\bar{v}_{i}(t)=v_{i}(t)-$ $v_{i}^{*}$, we obtain the closed-loop dynamic system as follows:

$$
\begin{aligned}
& \dot{v}_{i}(t)=\sum_{j=1}^{r} h_{j}\left(v_{i}, y_{i}\right) \\
& \cdot\left(a_{i j}\left(\bar{F}\left(y_{i}\left(t-\tau_{1}(t)\right)\right)-\bar{v}_{i}\left(t-\tau_{2}(t)\right)\right)\right) \\
& \dot{\bar{y}}_{i}(t)=\bar{v}_{i-1}(t)-\bar{v}_{i}(t) \quad(i=1,2, \ldots, N),
\end{aligned}
$$

where $\bar{v}_{i}\left(t-\tau_{2}(t)\right)=\bar{v}_{i}\left(t-\tau_{2}(t)\right)-v_{i}^{*}$ and $\bar{F}\left(y_{i}\left(t-\tau_{1}(t)\right)\right)=$ $F\left(y_{i}\left(t-\tau_{1}(t)\right)\right)-F\left(y_{i}^{*}\right)$.

If we set $\bar{y}(t)=\left[\bar{y}_{1}(t), \bar{y}_{2}(t), \ldots, \bar{y}_{n}(t)\right]$ and $\bar{v}(t)=\left[\bar{v}_{1}(t)\right.$, $\left.\bar{v}_{2}(t), \ldots, \bar{v}_{n}(t)\right]$, then (8) can be rewritten as follows:

$$
\begin{aligned}
\dot{\bar{v}}(t) & =\bar{A}(t) \bar{F}\left(y\left(t-\tau_{1}(t)\right)\right)-\bar{A}(t) \bar{v}\left(t-\tau_{2}(t)\right), \\
\dot{\bar{y}}(t) & =C_{1} \bar{v}(t),
\end{aligned}
$$

where

$$
\begin{aligned}
A_{j} & =\operatorname{diag}\left\{a_{1 j}, a_{2 j}, \ldots, a_{n j}\right\} ; \\
\bar{A}(t) & =\sum_{j=1}^{r} h_{j}(v, y) A_{j} ; \\
C_{1} & =\left[\begin{array}{rrrr}
-1 & 0 & 0 & \cdots \\
1 & -1 & 0 & \cdots \\
& \ldots & \ldots & \\
0 & \cdots & 1 & -1
\end{array}\right] .
\end{aligned}
$$

\section{The Stability Analysis of the Car-Following Model}

Theorem 1. Considering the car-following system (1), delay function $\tau_{i}(t)$ satisfies (2) for any given scalar $\varepsilon_{1}>0$. If $\alpha>0$ and the positive definite matrix $P_{i}, Q_{i}, R_{i}, i=1,2$, exist, then the following linear matrix inequality (LMI) holds: 


$$
\left[\begin{array}{cccc}
Q_{2}-\frac{1}{\tau_{2}} R_{2} & -A_{j}^{T} P_{1} & \frac{1}{\tau_{2}} R_{2} & C_{1}^{T} P_{2} \\
* & \left(d_{2}-1\right) Q_{2} & 0 & 0 \\
* & * & -\frac{1}{\tau_{2}} R_{2} & 0 \\
* & * & * & Q_{1}+\bar{\tau}_{1} C_{1}^{T} R_{1} C_{1}-\frac{1}{\tau_{1}} R_{1} \\
* & * & * & * \\
* & * & * & * \\
* & * & * & * \\
* & * & * & *
\end{array}\right.
$$

Thus, the fuzzy car-following model (5) satisfies asymptotic stability.

Proof. The Lyapunov-Krasovskii function $V(t)=V_{1}(t)+$ $V_{2}(t)+V_{3}(t)$ is constructed as follows:

$$
\begin{aligned}
V_{1}(t)= & \bar{v}^{T}(t) P_{1} \bar{v}(t)+\bar{y}^{T}(t) P_{2} \bar{y}(t), \\
V_{2}(t)= & \int_{t-\tau_{1}(t)}^{t} \bar{y}^{T}(s) Q_{1} \bar{y}(s) d s \\
& +\int_{t-\tau_{2}(t)}^{t} \bar{v}^{T}(s) Q_{2} \bar{v}(s) d s \\
V_{3}(t)= & \int_{-\bar{\tau}_{1}}^{0} \int_{t+\theta}^{t} \dot{\bar{y}}^{T}(s) R_{1} \dot{\bar{y}}(s) d s d \theta \\
& +\int_{-\bar{\tau}_{2}}^{0} \int_{t+\theta}^{t} \dot{\dot{v}}^{T}(s) R_{2} \dot{\bar{v}}(s) d s d \theta
\end{aligned}
$$

where $P_{i}, Q_{i}, R_{i}(i=1,2)$ is the positive definite matrix. Considering the given conditions (2) and the derivative of (19), we obtain the following expressions:

$$
\begin{aligned}
\dot{V}_{1} & (t)=\dot{\bar{v}}^{T}(t) P_{1} \bar{v}(t)+\bar{v}^{T}(t) P_{1} \dot{\bar{v}}(t)+\dot{\bar{y}}^{T}(t) P_{2} \bar{y}(t) \\
+ & \bar{y}^{T}(t) P_{2} \dot{\bar{y}}(t) \\
= & \left(\bar{A}(t) \bar{F}\left(y_{i}\left(t-\tau_{1}(t)\right)\right)-\bar{A}(t) \bar{v}\left(t-\tau_{2}(t)\right)\right)^{T} \\
\cdot & P_{1} \bar{v}(t)+\bar{v}^{T}(t) \\
\cdot & P_{1}\left(\bar{A}(t) \bar{F}\left(y_{i}\left(t-\tau_{1}(t)\right)\right)-\bar{A}(t) \bar{v}\left(t-\tau_{2}(t)\right)\right) \\
+ & \bar{v}^{T}(t) C_{1}^{T} P_{2} \bar{y}(t)+\bar{y}^{T}(t) P_{2} C_{1} \bar{v}(t),
\end{aligned}
$$

$$
\begin{aligned}
& \left.\begin{array}{cccc}
0 & 0 & A_{j}^{T} P_{1} & 0 \\
0 & 0 & 0 & -A_{j}^{T} R_{2} \\
0 & 0 & 0 & 0 \\
0 & \frac{1}{\tau_{1}} R_{1} & 0 & 0 \\
Q_{1}+\varepsilon_{1} \alpha^{2} I & 0 & 0 & 0 \\
* & -\frac{1}{\tau_{1}} R_{1} & 0 & 0 \\
* & * & -\varepsilon_{1} I & A_{j}^{T} R_{2} \\
* & * & * & -\frac{1}{\bar{\tau}_{2}} R_{2}
\end{array}\right]<0 \\
& j=1,2, \ldots, r .
\end{aligned}
$$

Using Jensen's inequality, we derive the following expression:

$$
\begin{aligned}
& \int_{t-\bar{\tau}_{1}}^{t} \dot{\bar{y}}^{T}(\theta) R_{1} \dot{\bar{y}}(\theta) d \theta \\
& \quad \geq \frac{1}{\bar{\tau}_{1}}\left(\int_{t-\bar{\tau}_{1}}^{t} \dot{\bar{y}}(\theta) d \theta\right)^{T} R_{1}\left(\int_{t-\bar{\tau}_{1}}^{t} \dot{\bar{y}}(\theta) d \theta\right) \\
& \quad=\frac{1}{\bar{\tau}_{1}}\left(\bar{y}(t)-\bar{y}\left(t-\bar{\tau}_{1}\right)\right)^{T} R_{1}\left(\bar{y}(t)-\bar{y}\left(t-\bar{\tau}_{1}\right)\right) .
\end{aligned}
$$


Similarly,

$$
\begin{aligned}
& \int_{t-\bar{\tau}_{2}}^{t} \dot{\bar{v}}^{T}(\theta) R_{2} \dot{\bar{v}}(\theta) d \theta \\
& \quad \geq \frac{1}{\bar{\tau}_{2}}\left(\int_{t-\bar{\tau}_{2}}^{t} \dot{\bar{v}}(\theta) d \theta\right)^{T} R_{2}\left(\int_{t-\bar{\tau}_{2}}^{t} \dot{\bar{v}}(\theta) d \theta\right) \\
& \quad=\frac{1}{\bar{\tau}_{2}}\left(\bar{v}(t)-\bar{v}\left(t-\bar{\tau}_{2}\right)\right)^{T} R_{2}\left(\bar{v}(t)-\bar{v}\left(t-\bar{\tau}_{2}\right)\right) .
\end{aligned}
$$

$$
\Omega=\sum_{j=1}^{r} h_{j}(v, y)
$$

We set $\Pi(t)=\left[\bar{v}(t), \bar{v}\left(t-\tau_{2}(t)\right), \bar{v}\left(t-\bar{\tau}_{2}\right), \bar{y}(t), \bar{y}\left(t-\tau_{1}(t)\right), \bar{y}(t-\right.$ $\left.\left.\bar{\tau}_{1}\right), \bar{F}\left(y_{i}\left(t-\tau_{1}(t)\right)\right)\right]$ using the Schur complement lemma. Thus, we obtain $\dot{V} \leq \Pi^{T}(t) \Omega \Pi(t)$ through the following expression:

$$
\begin{aligned}
\dot{V} & \leq \sum_{i=1}^{3} \dot{V}_{i}+\varepsilon_{1}\left(\alpha^{2} \bar{y}^{T}\left(t-\tau_{1}(t)\right) \bar{y}\left(t-\tau_{1}(t)\right)\right. \\
& \left.-\bar{F}^{T}\left(y_{i}\left(t-\tau_{1}(t)\right)\right) \bar{F}\left(y_{i}\left(t-\tau_{1}(t)\right)\right)\right) .
\end{aligned}
$$

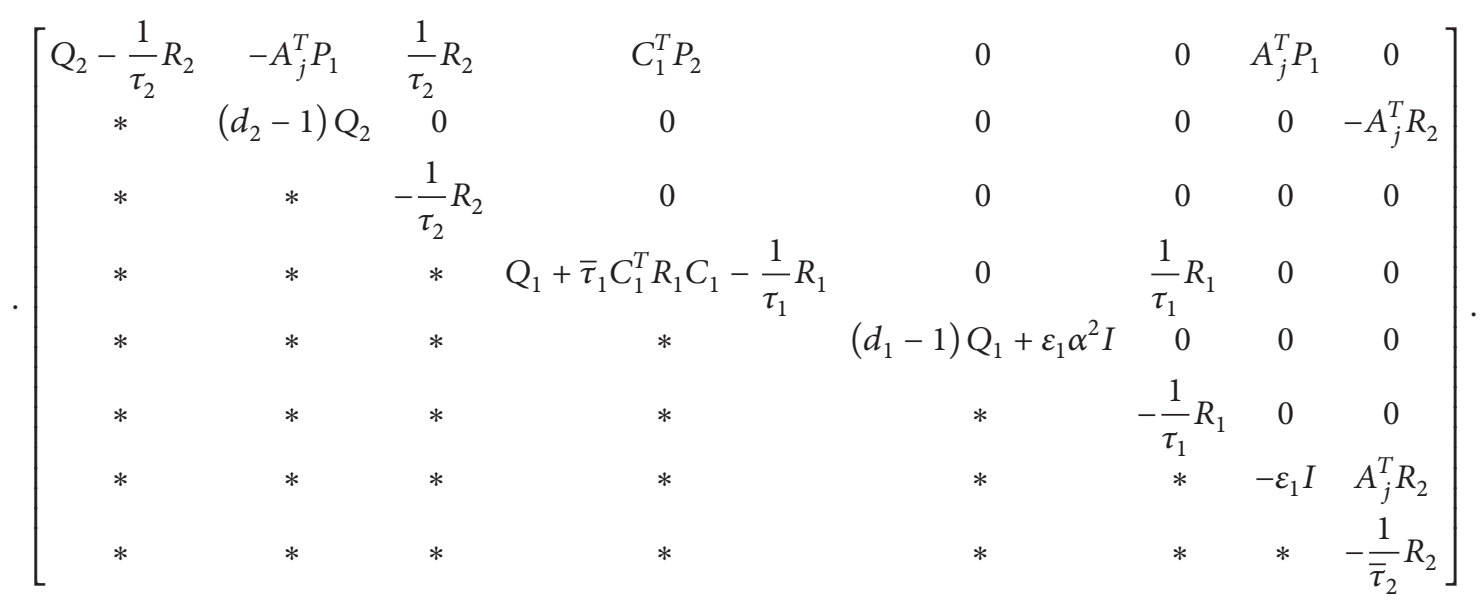

Using (11), we obtain $\dot{V}(t)<0$. Thus, the fuzzy car-following system (1) satisfies asymptotic stability.

\section{The Design of the Fuzzy Controller}

A local feedback controller is designed in each subsystem to suppress traffic congestion and ease traffic pressure as follows:

$$
\begin{array}{ll}
R^{t}: \text { if } & v_{i}(t) \text { is } M_{1}^{t} \text { and if } y_{i}(t) \text { is } M_{2}^{t} \\
\text { then } & u_{i t}(t)=k_{i t}\left(v_{i-1}(t)-v_{i}(t)\right),
\end{array}
$$

where $k_{i t}$ is the gain of the controller.

By synthesizing each local controller, we obtain the global fuzzy controller as follows:

$$
u_{i}(t)=\sum_{t=1}^{r} h_{j}\left(v_{i}, y_{i}\right)\left(k_{i t}\left(v_{i-1}(t)-v_{i}(t)\right)\right) .
$$

By applying controller (19) to the fuzzy car-following model (4), we obtain the closed-loop car-following system as follows:

$$
\begin{aligned}
& \dot{v}_{i}(t)=\sum_{j=1}^{r} \sum_{t=1}^{r} h_{j}\left(v_{i}, y_{i}\right) h_{t}\left(v_{i}, y_{i}\right) \\
& \cdot\left(a_{i j}\left(F\left(y_{i}\left(t-\tau_{1}(t)\right)\right)-v_{i}\left(t-\tau_{2}(t)\right)\right)\right.
\end{aligned}
$$

$$
\begin{aligned}
& \left.+k_{i t}\left(v_{i-1}(t)-v_{i}(t)\right)\right) \\
& \dot{y}_{i}(t)=v_{i-1}(t)-v_{i}(t) \quad(i=1,2, \ldots, N) .
\end{aligned}
$$

Based on the error variable $\bar{y}_{i}(t)=y_{i}(t)-y^{*}, \bar{v}_{i}(t)=v_{i}(t)-$ $v^{*}$, we obtain the following error dynamic equation through (8) and (20):

$$
\begin{aligned}
& \dot{\bar{v}}_{i}(t)=\sum_{j=1}^{r} \sum_{t=1}^{r} h_{j}\left(v_{i}, y_{i}\right) h_{t}\left(v_{i}, y_{i}\right) \\
& \cdot\left(a_{i j}\left(\bar{F}\left(y_{i}\left(t-\tau_{1}(t)\right)\right)-\bar{v}_{i}\left(t-\tau_{2}(t)\right)\right)\right. \\
& \left.\quad+k_{i t}\left(\bar{v}_{i-1}(t)-\bar{v}_{i}(t)\right)\right) \\
& \dot{\bar{y}}_{i}(t)=\bar{v}_{i-1}(t)-\bar{v}_{i}(t) \quad(i=1,2, \ldots, N) .
\end{aligned}
$$

By setting $\bar{y}(t)=\left[\bar{y}_{1}(t), \bar{y}_{2}(t), \ldots, \bar{y}_{n}(t)\right], \bar{v}(t)=\left[\bar{v}_{1}(t), \bar{v}_{2}(t)\right.$, $\left.\ldots, \bar{v}_{n}(t)\right],(21)$ can be rewritten as follows:

$$
\begin{aligned}
\dot{\bar{v}}(t)= & \bar{A} \bar{F}\left(y\left(t-\tau_{1}(t)\right)\right)-\bar{A} \bar{v}\left(t-\tau_{2}(t)\right) \\
& +\bar{K} C_{1} \bar{v}(t) \\
\dot{\bar{y}}(t)= & C_{1} \bar{v}(t),
\end{aligned}
$$


where $\bar{A}=\sum_{j=1}^{r} \sum_{t=1}^{r} h_{j}(v, y) h_{t}(v, y) A_{j}, \bar{K}=\sum_{j=1}^{r} \sum_{t=1}^{r} h_{j}(v$, y) $h_{t}(v, y) K_{t}, K_{t}=\operatorname{diag}\left\{k_{1 t}, k_{2 t}, \ldots, k_{n t}\right\}, A_{j}=\operatorname{diag}\left\{a_{1 j}, a_{2 j}\right.$, $\left.\ldots, a_{n j}\right\}$.

Theorem 2. Considering the closed-loop car-following system (22), the delay function $\tau_{i}(t)$ satisfies (2) for any given scalar $\varepsilon_{1}>0$. If $\alpha, \beta>0$ exists, then the positive definite matrix $P_{i}, Q_{i}, R_{i}, i=1,2$, and the appropriate dimension matrix $M_{j}(j=1,2, \ldots, r)$ ensure that the LMI holds:

$$
R_{2}<\beta P_{1} \text {, }
$$

$$
\begin{aligned}
& {\left[\begin{array}{cccccccc}
\left(M_{j} C_{1}\right)^{T}+M_{j} C_{1} & -\bar{A}^{T}(t) P_{1} & \frac{\beta}{\bar{\tau}_{2}} P_{1} & C_{1}^{T} P_{2} & 0 & 0 & A_{j}^{T} P_{1} & \left(M_{j} C_{1}\right)^{T} \\
+Q_{2}-\frac{\beta}{\bar{\tau}_{2}} P_{1}+\bar{\tau}_{1} C_{1}^{T} R_{1} C_{1} & & & & & & \\
* & \left(d_{2}-1\right) Q_{2} & 0 & 0 & 0 & 0 & 0 & -A_{j}^{T} P_{1} \\
* & * & -\frac{\beta}{\bar{\tau}_{2}} P_{1} & 0 & 0 & 0 & 0 & 0 \\
* & * & * & Q_{1}+\bar{\tau}_{1} C_{1}^{T} R_{1} C_{1}-\frac{1}{\bar{\tau}_{1}} R_{1} & 0 & \frac{1}{\bar{\tau}_{1}} R_{1} & 0 & 0 \\
* & * & * & * & \left(d_{1}-1\right) Q_{1}+\varepsilon_{1} \alpha^{2} I & 0 & 0 & 0 \\
* & * & * & * & * & -\frac{1}{\bar{\tau}_{1}} R_{1} & 0 & 0 \\
* & * & * & * & * & * & -\varepsilon_{1} I & A_{j}^{T} P_{1} \\
* & * & * & * & * & * & * & -\frac{1}{\beta \bar{\tau}_{2}} P_{1}
\end{array}\right]} \\
& <0 \quad j=1,2, \ldots, r
\end{aligned}
$$

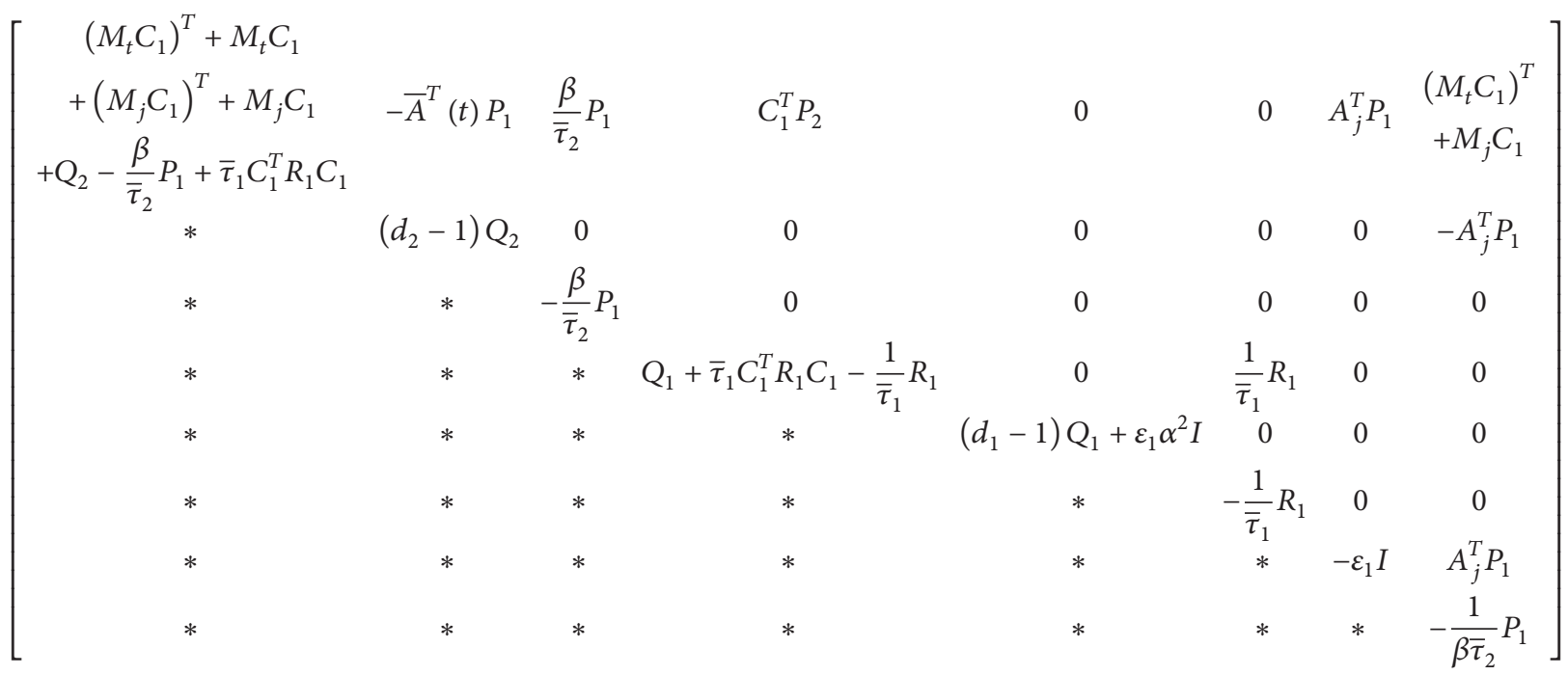

$<0 \quad t>j$.

Then, this means the existence of the fuzzy feedback controller (19), which makes the closed-loop car following system be stable, where the feedback gain matrix $K_{j}=P_{1}^{-1} M_{j}$.

Proof. Constructing the Lyapunov-Krasovskii function $V(t)$ like in the derivative of (12), we obtain the following expressions:

$$
\begin{gathered}
\dot{V}_{1}(t) \leq\left(\bar{A}(t) \bar{F}\left(y_{i}\left(t-\tau_{1}(t)\right)\right)-\bar{A}(t) \bar{v}\left(t-\tau_{2}(t)\right)\right. \\
\left.\quad+\bar{K} C_{1} \bar{v}(t)\right)^{T} P_{1} \bar{v}(t)+\bar{v}^{T}(t) P_{1}(\bar{A}(t)
\end{gathered}
$$

$$
\begin{gathered}
\cdot \bar{F}\left(y_{i}\left(t-\tau_{1}(t)\right)\right)-\bar{A}(t) \bar{v}\left(t-\tau_{2}(t)\right) \\
\left.+\bar{K} C_{1} \bar{v}(t)\right)+\bar{v}^{T}(t) C_{1}^{T} P_{2} \bar{y}(t)+\bar{y}^{T}(t) P_{2} C_{1} \bar{v}(t), \\
\dot{V}_{2}(t) \leq \bar{y}^{T}(t) Q_{1} \bar{y}(t)+\bar{v}^{T}(t) Q_{2} \bar{v}(t)-\left(1-d_{1}\right) \\
\cdot \bar{y}^{T}\left(t-\tau_{1}(t)\right) Q_{1} \bar{y}\left(t-\tau_{1}(t)\right)-\left(1-d_{2}\right) \bar{v}^{T}(t \\
\left.-\tau_{2}(t)\right) Q_{2} \bar{v}\left(t-\tau_{2}(t)\right),
\end{gathered}
$$




$$
\begin{aligned}
& \dot{V}_{3}(t)<\int_{-\bar{\tau}_{1}}^{0}\left(\dot{\bar{y}}^{T}(t) R_{1} \dot{\bar{y}}(t)\right. \\
& \left.-\dot{\bar{y}}^{T}(t+\theta) R_{1} \dot{\bar{y}}(t+\theta)\right) d \theta \\
& +\beta \int_{-\bar{\tau}_{2}}^{0}\left(\dot{\bar{v}}^{T}(t) P_{1} \dot{\bar{v}}(t)\right. \\
& \left.-\dot{\bar{v}}^{T}(t+\theta) P_{1} \dot{\bar{v}}(t+\theta)\right) d \theta=\bar{\tau}_{1} \dot{\bar{y}}^{T}(t) R_{1} \dot{\bar{y}}(t) \\
& +\beta \bar{\tau}_{2} \dot{\bar{v}}^{T}(t) P_{1} \dot{\bar{v}}(t)-\int_{t-\bar{\tau}_{1}}^{t} \dot{\bar{y}}^{T}(\theta) R_{1} \dot{\bar{y}}(\theta) d \theta
\end{aligned}
$$$$
-\beta \int_{t-\bar{\tau}_{2}}^{t} \dot{\bar{v}}^{T}(\theta) P_{1} \dot{\bar{v}}(\theta) d \theta .
$$

Using Jensen's inequality, we derive the following expression:

$$
\begin{aligned}
\dot{V} & \leq \sum_{i=1}^{3} \dot{V}_{i}+\varepsilon_{1}\left(\alpha^{2} \bar{y}^{T}\left(t-\tau_{2}(t)\right) \bar{y}\left(t-\tau_{2}(t)\right)\right. \\
& \left.-\bar{F}^{T}\left(y_{i}\left(t-\tau_{1}(t)\right)\right) \bar{F}\left(y_{i}\left(t-\tau_{1}(t)\right)\right)\right) .
\end{aligned}
$$

Then, we define $\Pi(t)=\left[\bar{v}(t), \bar{v}\left(t-\tau_{2}(t)\right), \bar{v}\left(t-\bar{\tau}_{2}\right), \bar{y}(t), \bar{y}(t-\right.$ $\left.\left.\tau_{1}(t)\right), \bar{y}\left(t-\bar{\tau}_{1}\right), \bar{F}\left(y_{i}\left(t-\tau_{1}(t)\right)\right)\right]$. By applying the Schur complement lemma, we obtain $\dot{V} \leq \Pi^{T}(t) \Omega \Pi(t)$ :

$\Omega=\sum_{j=1}^{r} h_{j}^{2}(v, y)$

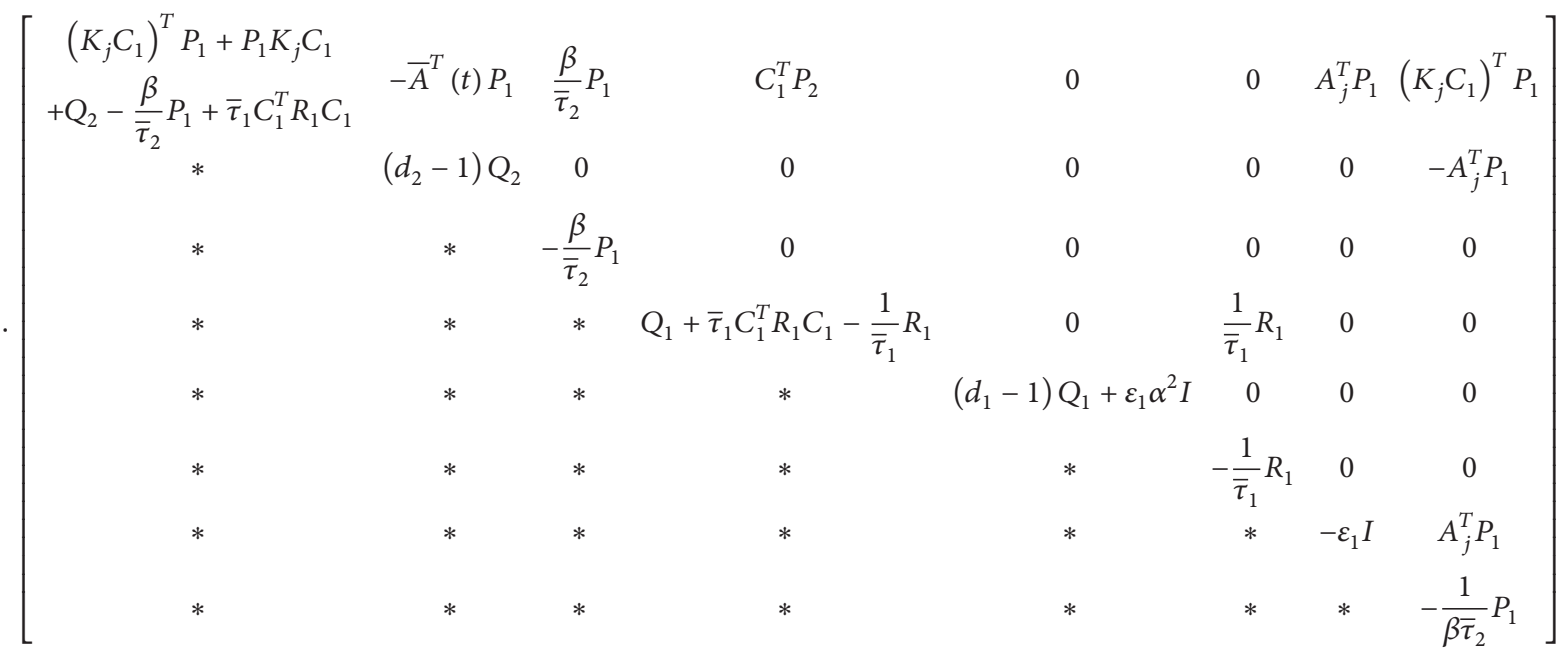

$$
\begin{aligned}
& +\sum_{j=1}^{r} \sum_{j<t}^{r} h_{j}(v, y) h_{t}(v, y)
\end{aligned}
$$

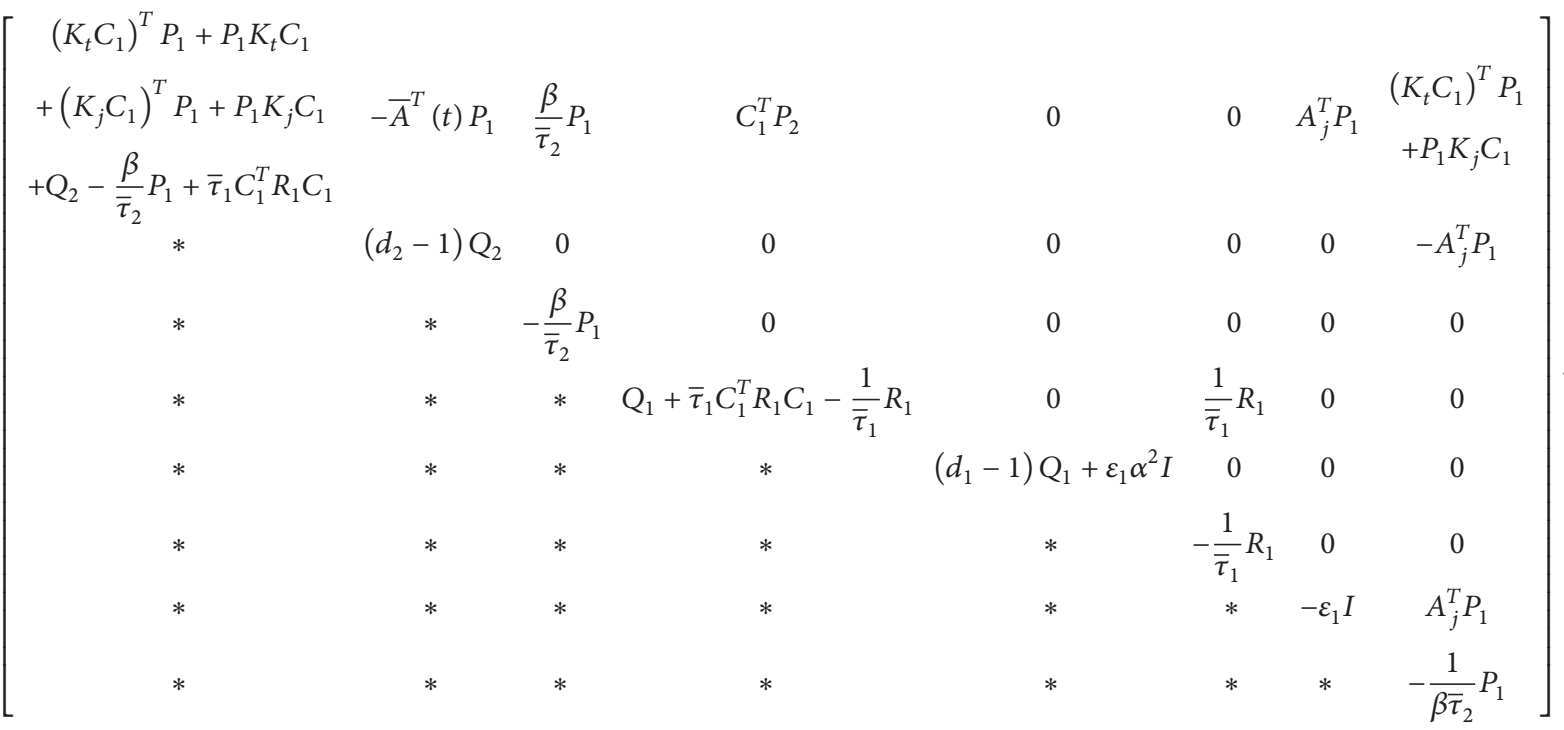


We set $M_{j}=K_{j} P_{1}$. Using (24), we obtain $\dot{V}(t)<0$. Thus, the closed-loop car-following system (22) satisfies asymptotic stability.

\section{Numerical Simulation}

Assuming that 11 cars are running on a single lane without overtaking under an open boundary and the head car runs at constant speed $v_{0}=0.964 \mathrm{~m} / \mathrm{s}$, maximum speed $v_{\max }=$ $2 \mathrm{~m} / \mathrm{s}$, and safe distance $y_{c}=2 \mathrm{~m}$ according to the literature [13], the delay function of the sensing speed and headway is set as follows:

$$
\begin{aligned}
& \tau_{1}(t)=0.25+0.15 \cos (t) \\
& \tau_{2}(t)=0.25+0.1 \cos (t),
\end{aligned}
$$

where $\bar{\tau}_{1}=0.4, \bar{\tau}_{2}=0.1, d_{1}=0.35, d_{2}=0.15$. Speed and headway are initialized as follows:

$$
\begin{aligned}
y_{i}(t) & =2, \\
t & \in\left[-\bar{\tau}_{1}, 0\right], \\
v_{i}(t) & =0.964, \\
t & \in\left[-\bar{\tau}_{2}, 0\right] .
\end{aligned}
$$

For convenience, we introduced fuzzy control theory and categorized sensitivity into strong, moderate, and weak, as well as speed and headway into three categories; the specific division and fuzzy rules can be obtained from Figure 2 .

We assume that the velocity of the head car was reduced to zero, thus suffering external disturbances between $100 \mathrm{~s}$ and 102 s. Figure 3(a) shows the speed-time curve of cars 1, 6, and 11 without the controller. Figure 3(b) indicates the speed of all vehicles with the time image between $90 \mathrm{~s}$ and $200 \mathrm{~s}$. Figure 3(c) describes the space-time image of all the cars. When the head car suffers external interference, the speed of each vehicle is significantly affected and the headway exhibits severe fluctuations. Moreover, the return of each vehicle to the desired velocity $v_{0}$ should entail substantial time. Thus, traffic congestion easily occurs.

By solving Theorem 2, the fuzzy controller is obtained. Figure 4(a) illustrates the speed curve of vehicles 1, 6, and 11 with a fuzzy controller. Figure 4(b) shows the speed-time image of all vehicles with the fuzzy controller. Figure 4(c) depicts the headway-time image of all vehicles with the fuzzy controller. Figure 4 indicates that the convergence capability of the vehicles is strengthened. Moreover, the time that the vehicle speed returns to the stable state and the vibration range between the vehicle headway decreases. Thus, the fuzzy controller effectively suppresses traffic congestion.

The simulation results verified the efficiency of the fuzzy controller in reducing fuel consumption and exhaust

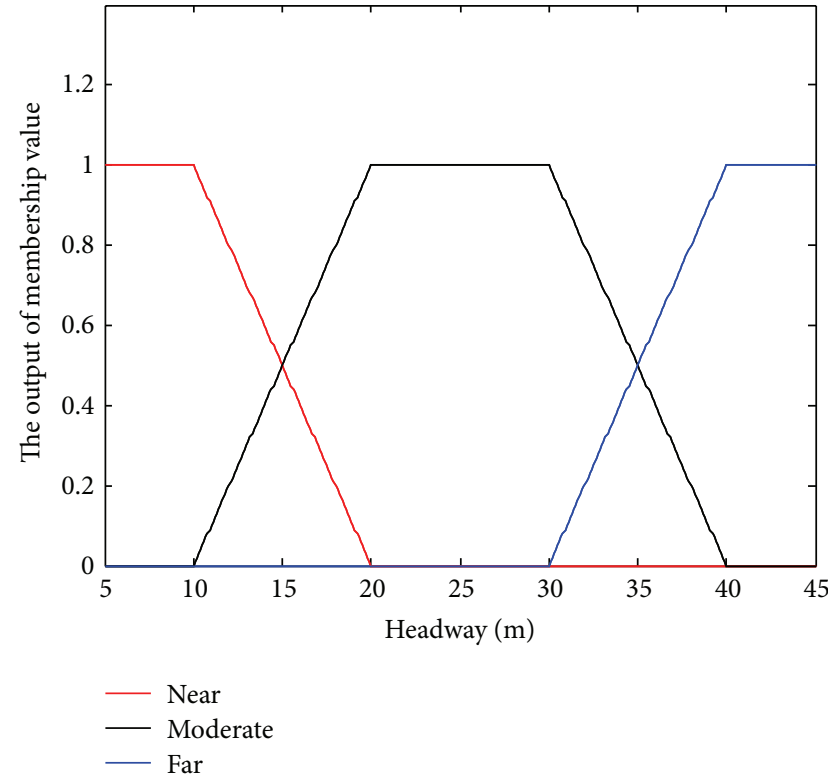

(a)

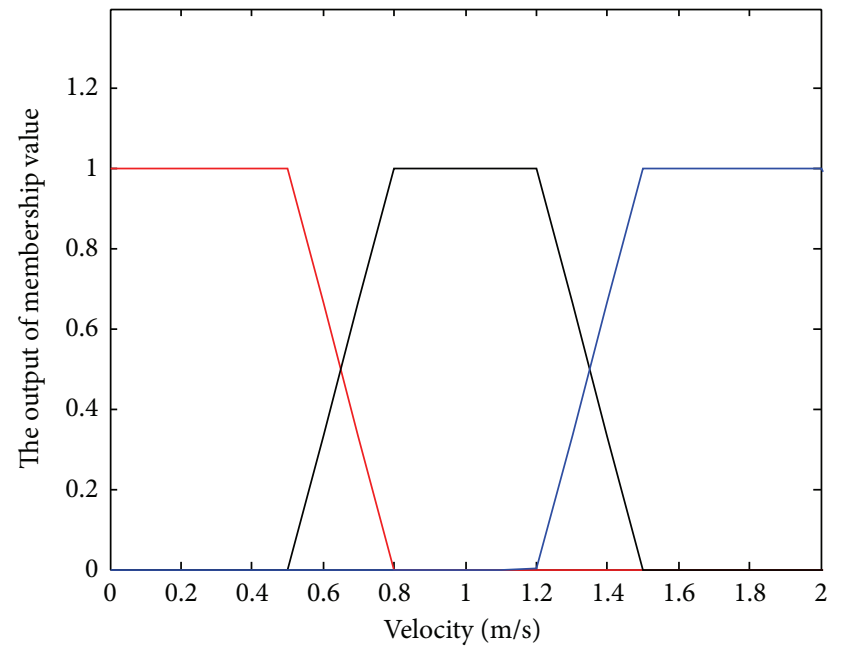

— Slower
- Moderate
Fast

(b)

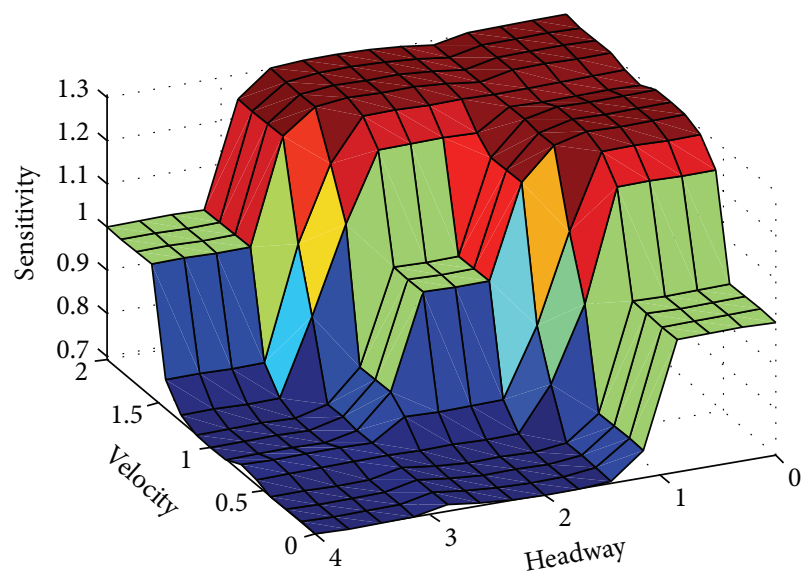

(c)

FIgURE 2: Membership functions of speed and headway and the input or output of curved surfaces. 


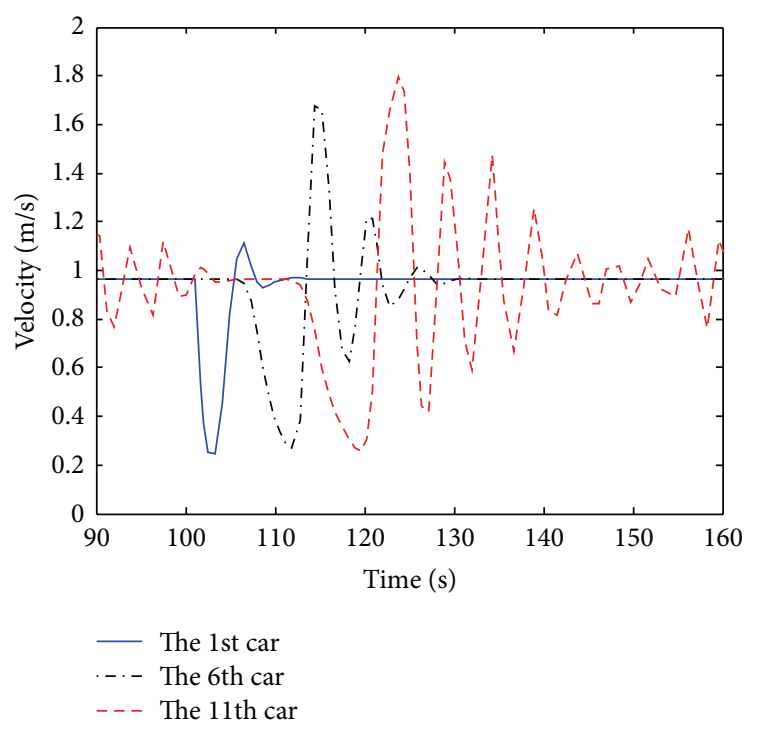

(a)

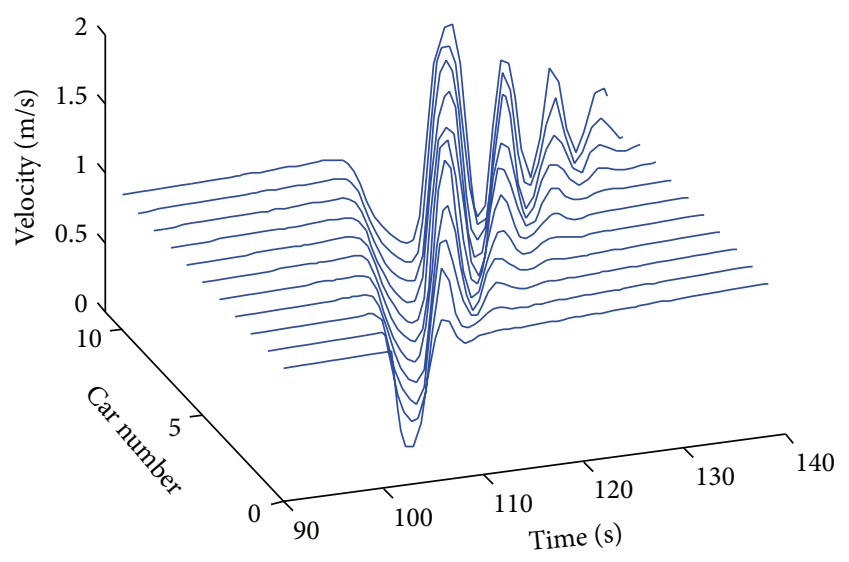

(b)

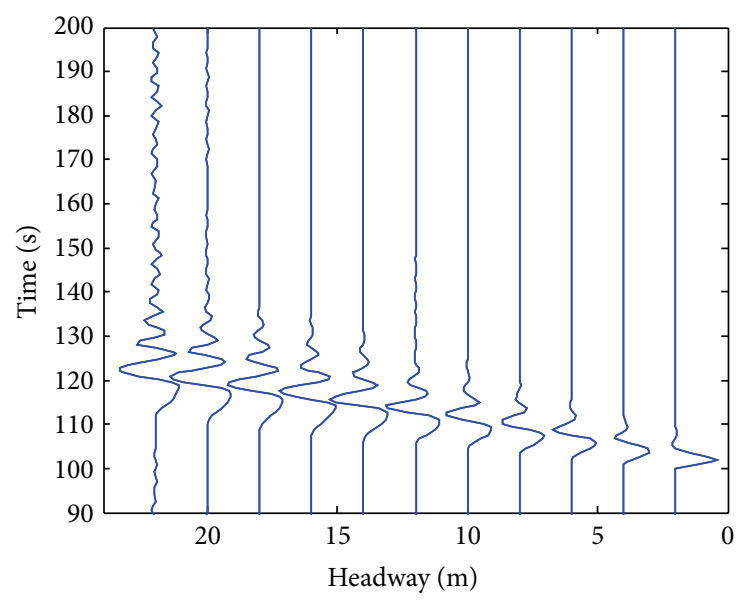

(c)

FIGURE 3: Car-following model without the controller: (a) speed-time image of vehicles 1, 6, and 11, (b) speed-time image of all vehicles, and (c) headway-time image.

emissions. The traffic emission model is time-consuming. Thus, we applied the VT-Micro model in the present work [14]. This model mainly demonstrates the relationship of fuel consumption and exhaust emission with the speed and acceleration of a vehicle. The relationship is deduced from the following equation:

$$
\operatorname{In}(\mathrm{MOEe})=\sum_{i=0}^{3} \sum_{j=0}^{3}\left(K_{i, j}^{e} \times v_{i} \times\left(\frac{d v}{d t}\right)^{j}\right),
$$

where MOEe represents the instant emission or the instant fuel consumption ratio.

$K_{i, j}^{e}$ represents the related regression coefficient, and the specific value can be obtained from literature [14].

Figure 5 demonstrates the curve of the cumulative fuel consumption with the emission of $\mathrm{CO}, \mathrm{HC}$, and $\mathrm{NO} x$ in vehicles with and without the fuzzy controller. The exhaust emissions and fuel consumption of vehicles with the fuzzy controller are lower than those without the fuzzy controller. This result verifies that the fuzzy controller effectively reduces fuel consumption and exhaust emissions.

\section{Conclusion}

Considering the driver existence, the time delay, when drivers sense headway and velocity, and the sensitivity of drivers fluctuate with headway and velocity. Based on this, a class of T-S fuzzy car-following model and the stability of this model are investigated. Using the Lyapunov function, the sufficient condition that the fuzzy controller exists is given, which makes the closed-loop car following model satisfy the asymptotic stability, and by solving the LMI, we can 


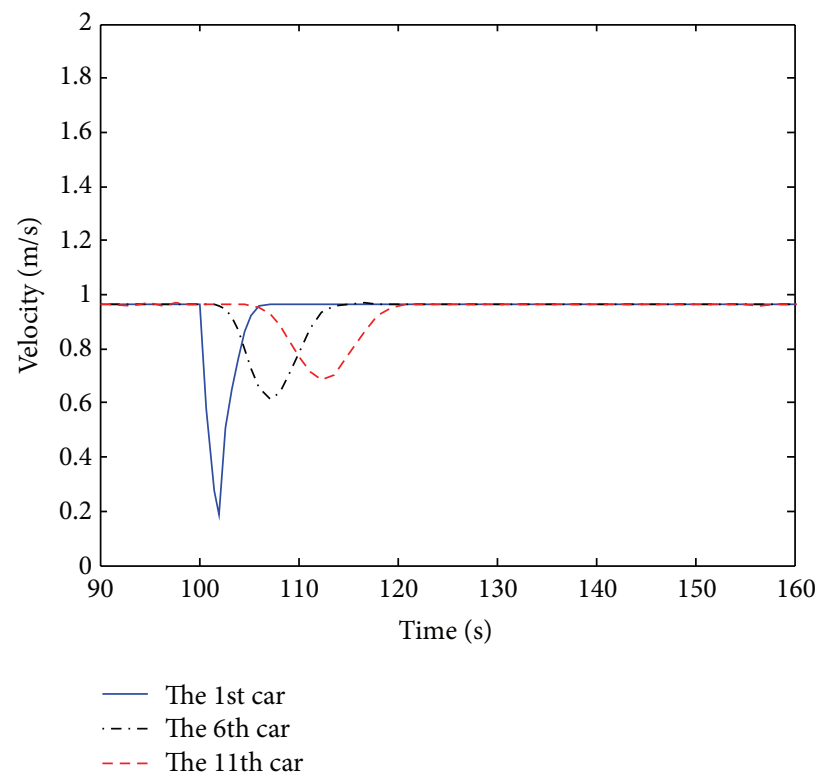

(a)

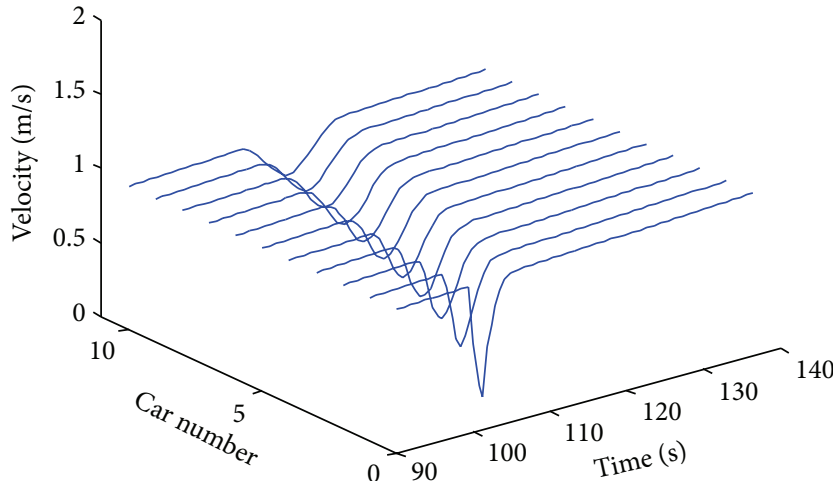

(b)

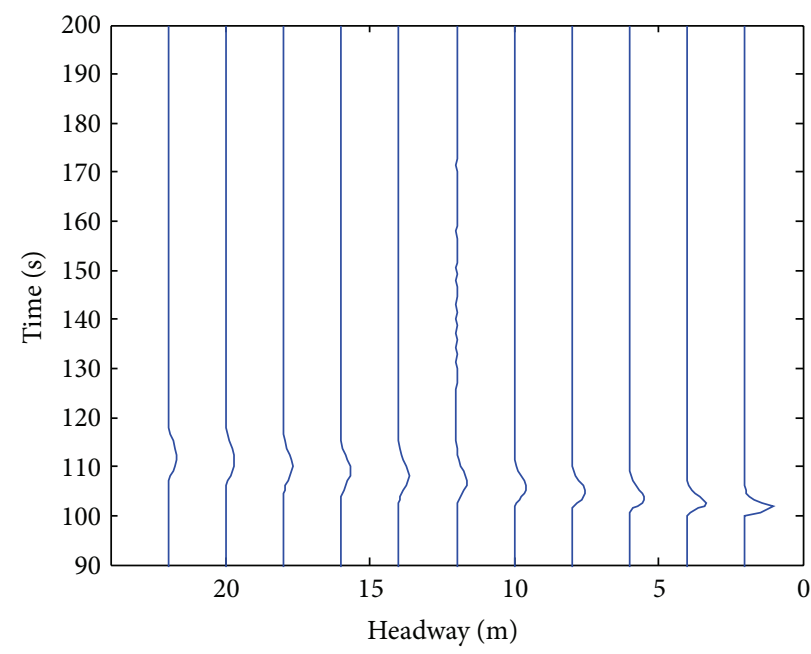

(c)

Figure 4: Car-following model under the fuzzy controller: (a) speed-time image of vehicles 1, 6, and 11, (b) speed-time image of all vehicles, and (c) headway-time image.

obtain the fuzzy controller. We compared the velocity-time image and headway-time image of the following cars with and without the fuzzy controller when the head car suffers external disturbance. The velocity and headway fluctuation of all the vehicles were effectively alleviated. Vehicles with the fuzzy controller equilibrated faster than vehicles without the fuzzy controller; meanwhile the fuzzy controller can effectively reduce the exhaust emission and fuel consumption. This research can promote the development of the car-following model. This method can be applied to the controller design of autonomous cars in a connected vehicle network environment. However, the current research only focuses on vehicles running in a single lane. We will continue to investigate the car-following behavior in more complex environments.

\section{Competing Interests}

The authors declare that they have no competing interests.

\section{Acknowledgments}

This work is supported by the National Natural Science Foundation of China (51408237). 


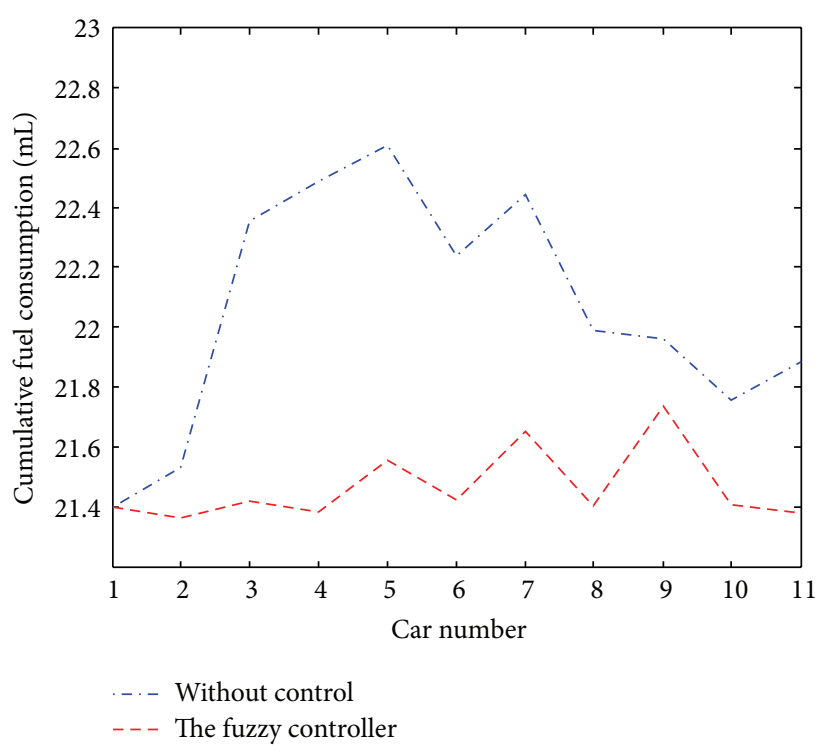

(a)

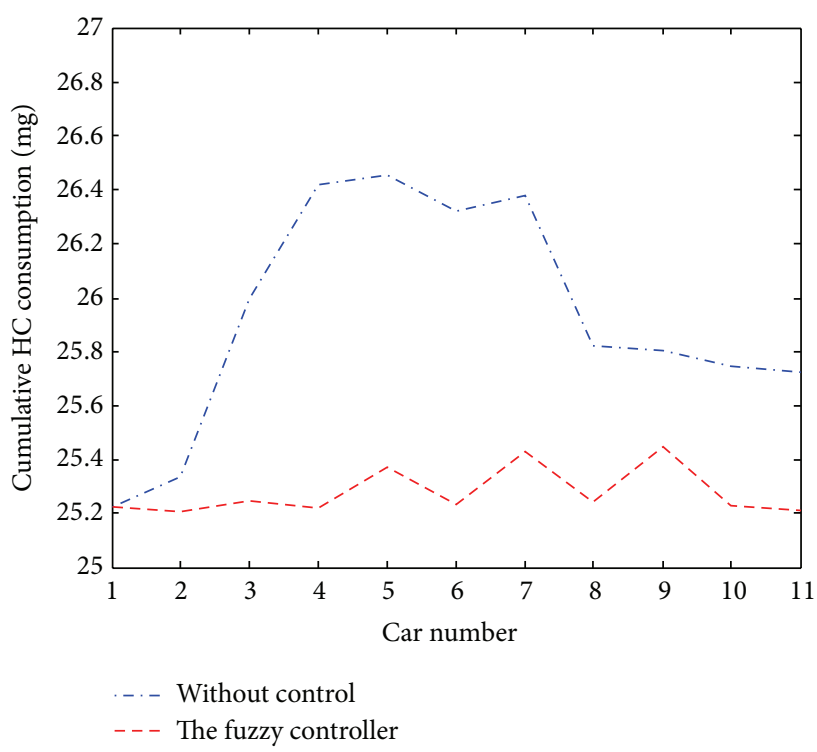

(c)

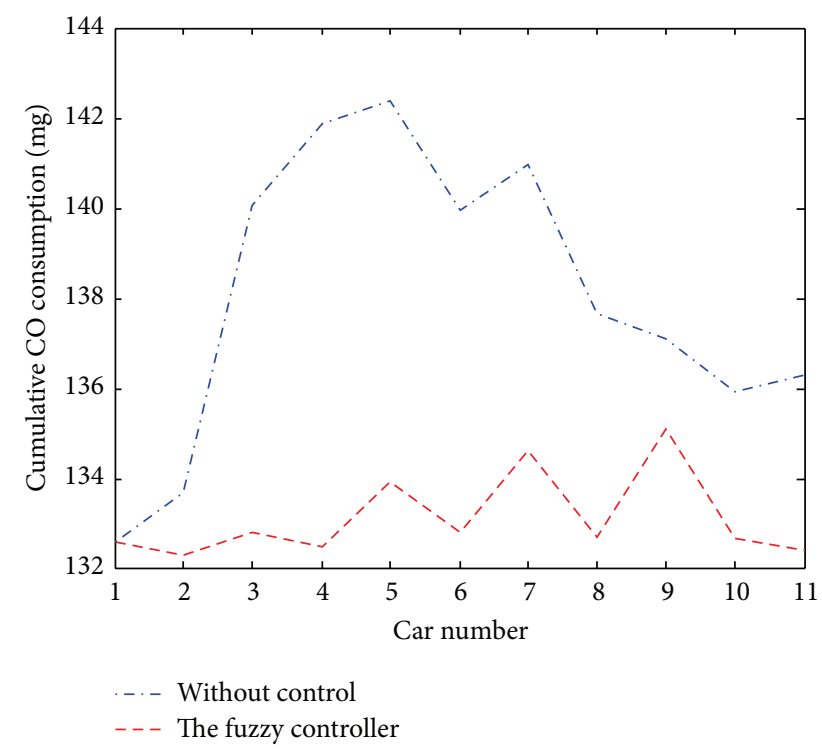

(b)

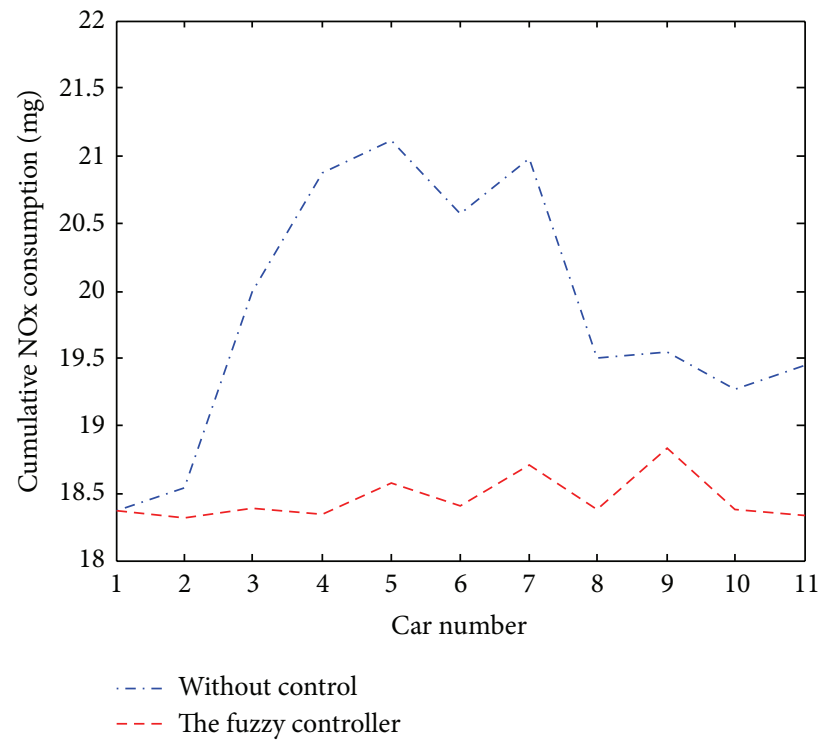

(d)

Figure 5: (a) Fuel consumption, (b) CO emission, (c) HC emission, and (d) NO $x$ emission of all vehicles during periods of $t=140 \mathrm{~s}$.

\section{References}

[1] S. Yu, M. Huang, J. Ren, and Z. Shi, "An improved car-following model considering velocity fluctuation of the immediately ahead car," Physica A: Statistical Mechanics \& Its Applications, vol. 449, pp. 1-17, 2016.

[2] G. Zhang, M. Zhao, D.-H. Sun, W.-N. Liu, and H.-M. Li, "Stabilization effect of multiple drivers' desired velocities in car-following theory," Physica A: Statistical Mechanics and Its Applications, vol. 442, pp. 532-540, 2016.

[3] D. Sun, Y. Kang, and S. Yang, "A novel car following model considering average speed of preceding vehicles group," Physica A: Statistical Mechanics \& Its Applications, vol. 436, pp. 103-109, 2015.

[4] L. Liu, L. Zhu, and D. Yang, "Modeling and simulation of the car-truck heterogeneous traffic flow based on a nonlinear car-following model," Applied Mathematics and Computation, vol. 273, pp. 706-717, 2016.

[5] M. Saifuzzaman, M. M. Haque, Z. Zheng, and S. Washington, "Impact of mobile phone use on car-following behaviour of young drivers," Accident Analysis \& Prevention, vol. 82, pp. 1019, 2015.

[6] T.-Q. Tang, W.-F. Shi, H.-Y. Shang, and Y.-P. Wang, "An extended car-following model with consideration of the reliability of inter-vehicle communication," Measurement, vol. 58, pp. 286-293, 2014.

[7] B. D. Reichardt, M. Miglietta, L. Moretti et al., "CarTALK 2000: safe and comfortable driving based upon inter-vehiclecommunication," in Proceedings of the IEEE Intelligent Vehicle Symposium, pp. 545-550, Versailles, France, June 2002.

[8] B. S. Kerner, S. L. Klenov, and A. Brakemeier, "Testbed for wireless vehicle communication: a simulation approach based 
on three-phase traffic theory," in Proceedings of the IEEE Intelligent Vehicles Symposium, pp. 180-185, IEEE, Eindhoven, The Netherlands, June 2008.

[9] F. Knorr and M. Schreckenberg, "Influence of inter-vehicle communication on peak hour traffic flow," Physica A: Statistical Mechanics \& Its Applications, vol. 391, no. 6, pp. 2225-2231, 2012.

[10] B. Dalla Chiara, F. Deflorio, and S. Diwan, "Assessing the effects of inter-vehicle communication systems on road safety," IET Intelligent Transport Systems, vol. 3, no. 2, pp. 225-235, 2009.

[11] T.-Q. Tang, H.-J. Huang, W.-X. Wu, and Y.-H. Wu, "Analyzing trip cost with no late arrival under car-following model," Measurement, vol. 64, pp. 123-129, 2015.

[12] W.-X. Zhu and L.-D. Zhang, "Analysis of car-following model with cascade compensation strategy," Physica A: Statistical Mechanics and Its Applications, vol. 449, pp. 265-274, 2016.

[13] S. P. Hoogendoorn and S. Ossen, "Parameter estimation and analysis of car-following models," in Proceedings of the 16th International Symposium on Transportation and Traffic Theory: Flow, Dynamics and Human Interaction, 2005.

[14] T.-Q. Tang, Q. Yu, S.-C. Yang, and C. Ding, "Impacts of the vehicle's fuel consumption and exhaust emissions on the trip cost allowing late arrival under car-following model," Physica A: Statistical Mechanics and Its Applications, vol. 431, pp. 52-62, 2015. 


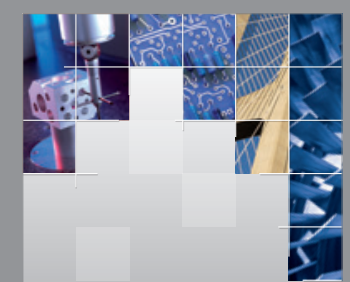

\section{Enfincering}
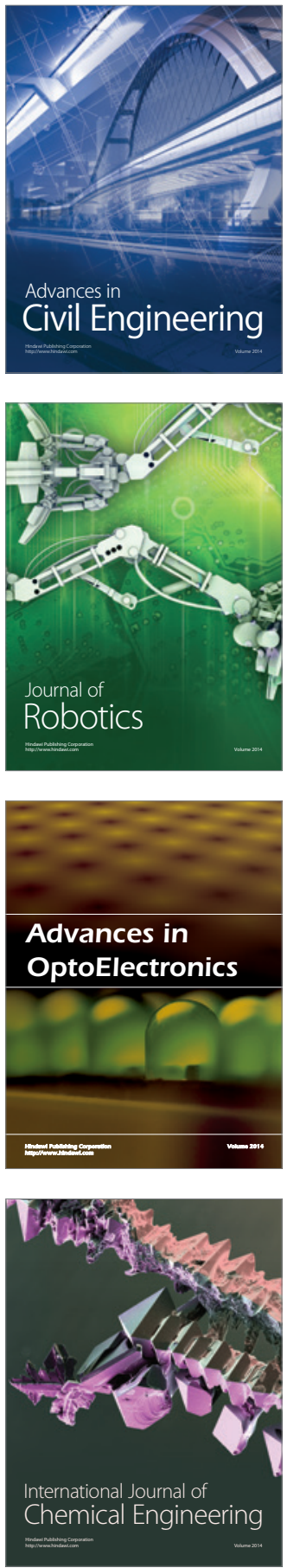

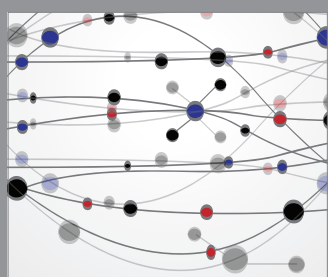

The Scientific World Journal

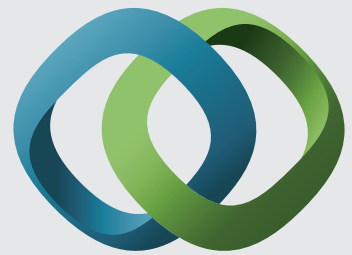

\section{Hindawi}

Submit your manuscripts at

http://www.hindawi.com
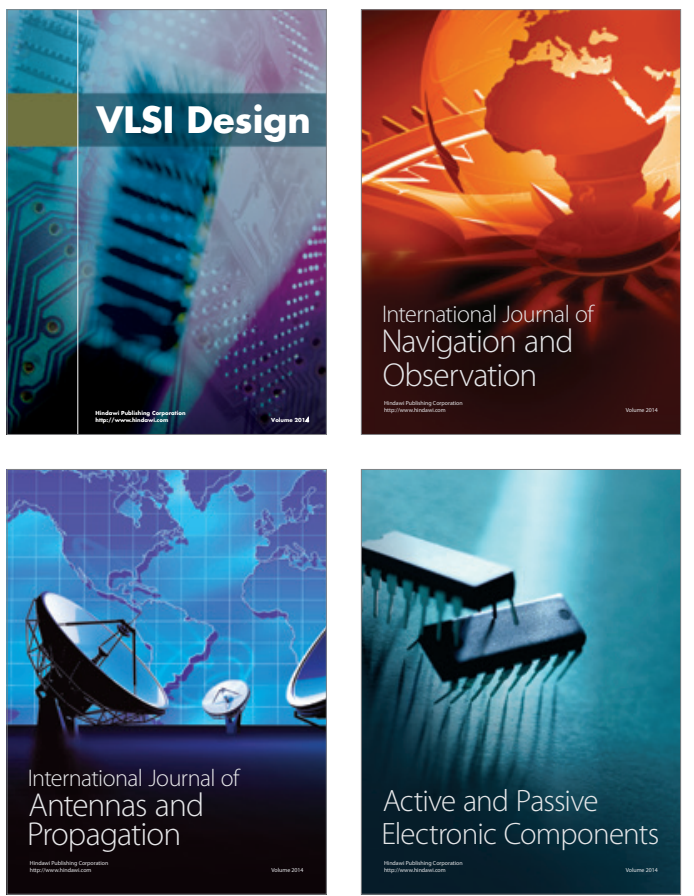
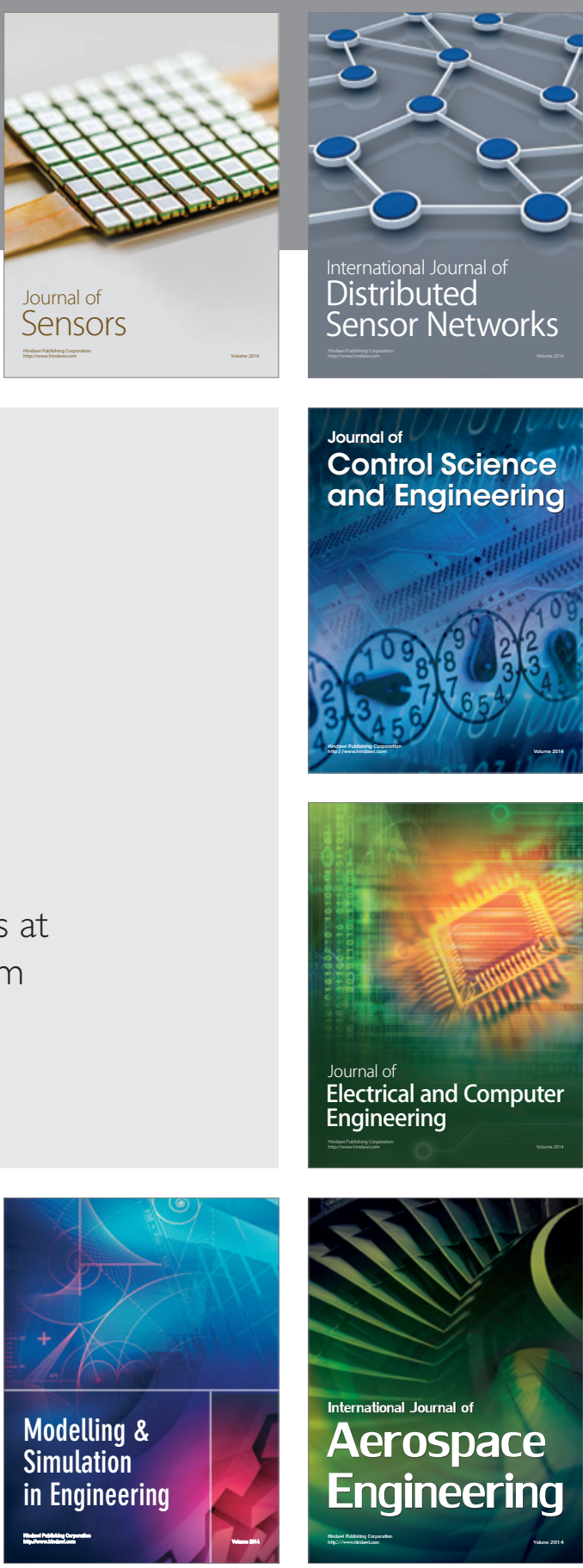

International Journal of

Distributed

Sensor Networks

Journal of

Control Science

and Engineering
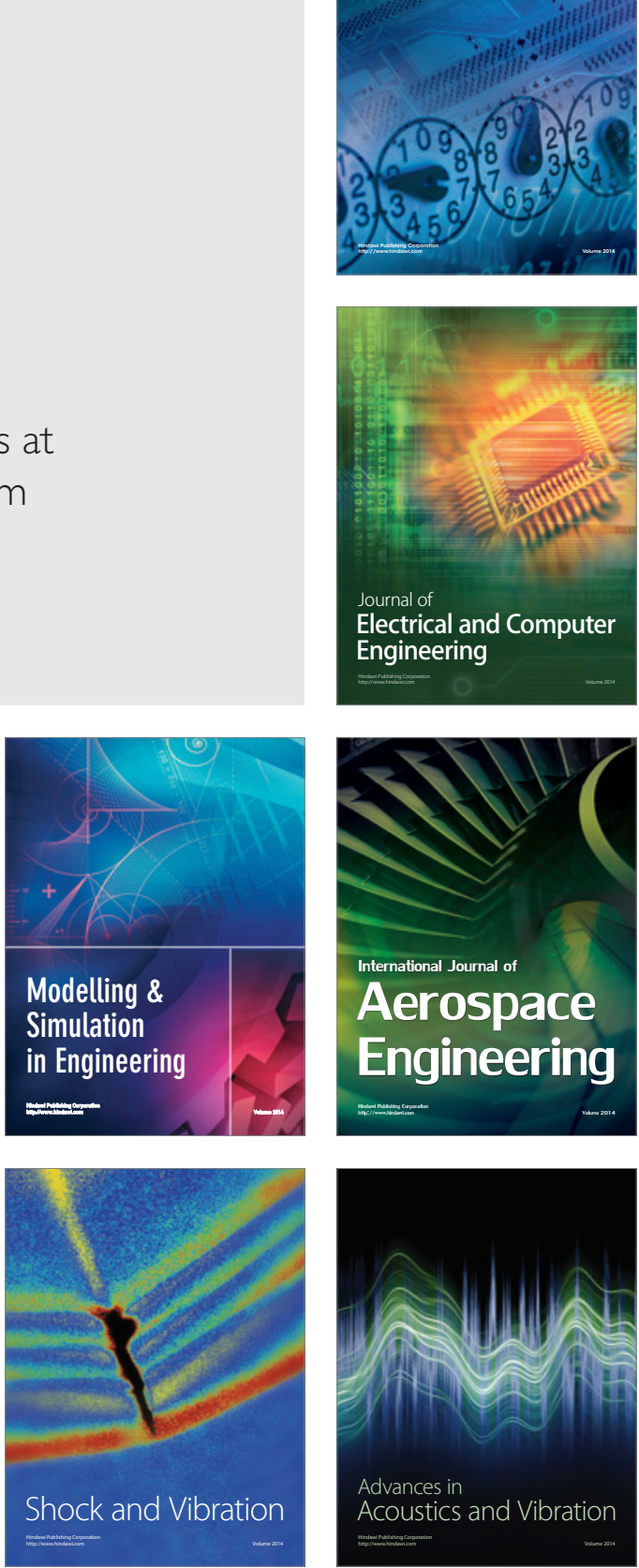